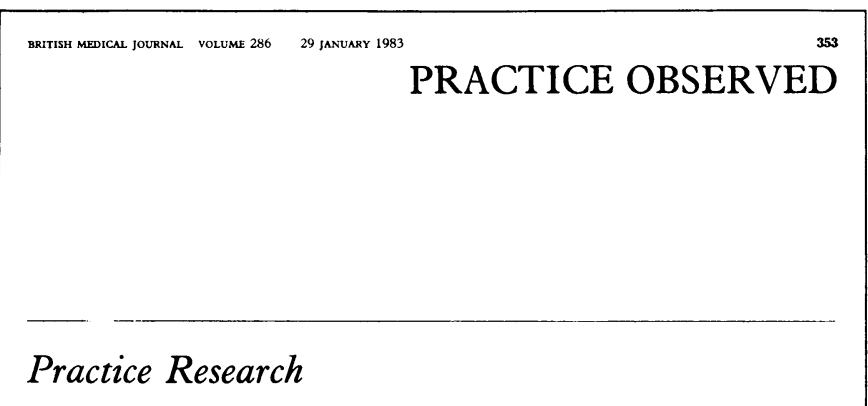

\section{Newcastle vocational trainees 1976-80: are they doing the work they wanted?}

NEWCASTLE BRANCH OF WOMEN IN MEDICINE*
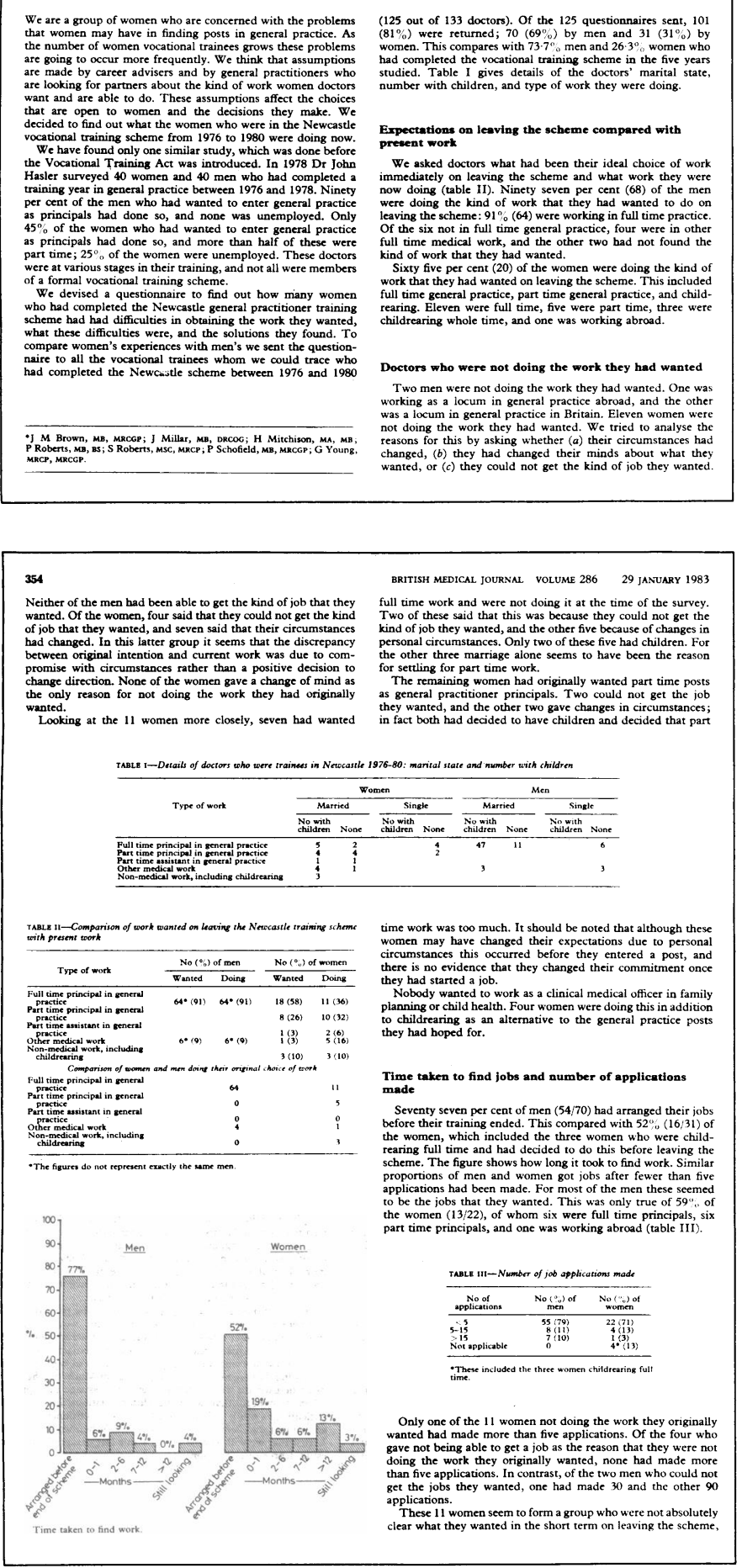

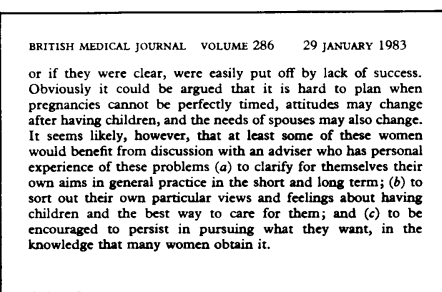

Other factors

Geographical area-The results of our survey showed, as ex-
pected, that women arem much more offen influenced by their
spouses' employment when considering where they will work

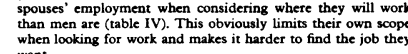

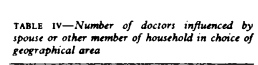

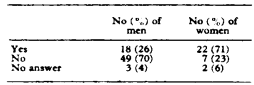

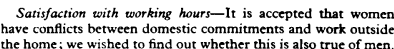

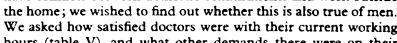

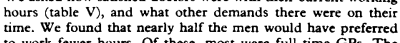

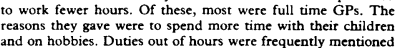

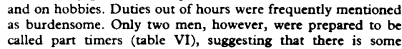

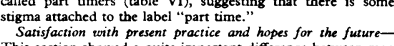

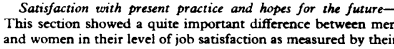

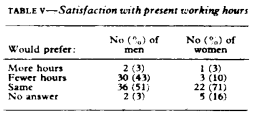

TABLL Vi-IAcal work 10-15 years from now

tucal workt 10-15
years from now

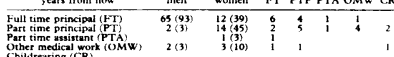
(1) (1)
356

tend to have narrow views about what are the right jobs for
women. It is imperative that careers advisers and future $G P$ colleagues do not have preconceived ideas about the kind of
work women want and are capable of doing. Should medical unemployment become a reality it is clear that these discriminat-
ory views will adversely affect iob opportunities for women. example in taking on fullt time women partners sor putting them
forward as trainers. Inded, the results of our survey suggest that Perhaps the point of greatest practical value to women
starting a carcer in general practice is that their aims can be of what thesc aims are and requires perseverancec in the face of

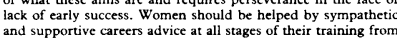

\section{BRITISH MEDICAL JOURNAL VOLUME $286 \quad 29$ JANUARY 1983 to be encountered. work, but the results of the survey have also raised some other
points. Men also require greater flexibility at work and would often like to work less and spend more time with their families.
They, too, are constrained by expectations of men's role at work and their craditional family roles. Investigation of these areas
will probably provide the major contribution to improving iob
satisfaction for both men and women \\ We would like to thank Mrs P Patton and Miss M Burtt for secretarial help.
Correspondence should be addressed to Dr Gail Young, 8 Dilston
Terrace, Newastle upon Tyne NE3 1 XX. (Accepted 2 Novermber 1982?}

\title{
Thinking About the Unthinkable
}

\section{Divorce}

The incidence of divorce has reached about one in three marri-
ages, and medical marriages are no exception. Divorce, by definition, is dissuptive, the amount of dissuption varying according
to circumstances. To a general practitioner this can create
many problems, both practical and emotional. The general practitioner is concerned in human relationships and inte-
actions; counselling is becoming a more important part of medcine. He tries to remain objective in his management and hopes
that his avvice will be heeded, but he may still fail in his own
relationshe Is the relationships. Is this because he becomes too involved in
work that h h does not see the problems at home? I I he too
obiective in his attitudes so that the subjective problems are no objective in his attitudes so that the subjective problems are
recognised Doos the fact that he has a very busy profession
life mean that he loses tolerance at home? Marriage is a partureshhip two peopple comminting themselves
to each other to share all the ioys and difficulties of life. It is totail commitment and still largely given on a religious basis
Life is never smooth, but a married couple should learn to cope
wict he problems together Probably the most important factor with the problems together. Probably the most important factor
is trust. It is extremely difficult to maintain a marriage on
suspicion, and abusing such trust is a dangerous pastime in any suspicion, and abusing such trust is a dangerous pastime in any
rclationship.
When any relationship breaks therc are always personal trat When any relationship breaks therc are always personal trau-
mas, and mine was no different. The emotional involvement in marriage is deep and trusting, and this cannot readily be cas
aside, particularly if your wife rejects you. There is a marked
difference in the emotional reaction between the breakdown of difference in the emotional reaction between the breakdown of
marriage and deaath. In death there is a finality and it occurs martrage and death. In death here is a finatity and ir occurs
when there is still love and happiness in the marriage in marri-
age breakdown animosity and hatred can, and usually does, reage breakd
place love. place love.
when mife first left me for another man I felt rejected,
humiliated, and a social outcast As in many other marriage
breakdowns, my wife preferred the company of a good friend of breakdowns, my wife preferered the company of a good friend of
ours. Deceit had built up in the final weecs of our manriage
without my realising it. Howevere, as I s sull loved and trusted her, I was suddealy told that she was leaving me to go to her
mother's "to think things over" and would leave me to look

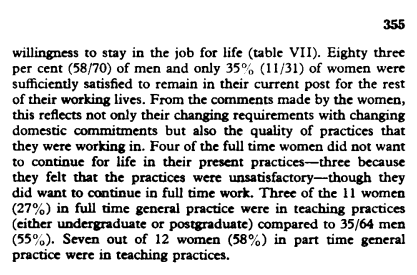

TABLI vil-Number of docters wantivs to remain in presemt work for bje

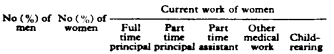

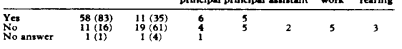

Ideal work $10-15$ years from now-With one exception, all of
the women who are not working as principals in general practice the women who are not working as principals in general practice
hope to be working as principals in future, two full time and want to move back into possts as general practitioner principals

Conclusion

We did this survey to find out the sort of problems that
women encounter in obtaining work after completing the women encounter in obtaining work after completing the
Newcastle vocational training scheme. We felt that there were
commonly held misconceptions about what women are doing and what they actually want to do, and we wanted to clarify this. Most women who completed the vocational training scheme
intended to work as principals in general practice. At the time

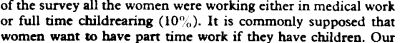
women want to have paring time work cif they have che children. Our
survey showed that women with children are as likely to want survey showed that women with children are as likely to want
to work full inte as part ite. In fact, as many mothers work
full time successfully as part time. Nearly half (8hit) of the women with children wanted to work full time, and nearly half
$(5 / 11)$ of the women working full time had children (5/1) of the women working full time had children.
From this it is obvious that there is no one solution to the
problem of combining work and family life for women. Some problem of combining work and family lite for women. Some
women would wish to work full time while their children are women would wish to work full time while their children are
young; ; thers would prefert to be at home for some or all of that
time. Changing personal circumstances may lead to changes in iob requirements, but this is not inevitable
The results of our survey showed that if for women to get the kind of jobs they want. Only $65 \%$ of women in our sample were doing the work that they originally
wanted compared to $97^{\circ}$, of the men. There are many pressures on women to compromise and accept less than they had hoped
for. This is reflected in the fact that the women made fewer applications for iobs than the men and took wobs with which they
were not fully satifficd."The pressures include soegh hicy the husband's job to take precedence over that of the wife, and the attiudes prevalent in society towards women and work. were not fully satisfied. The pressures include geographical
limitations, the needs of spouses and children, the tendency for

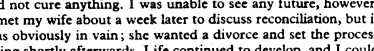

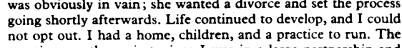

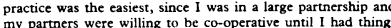

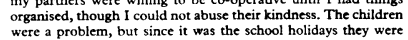




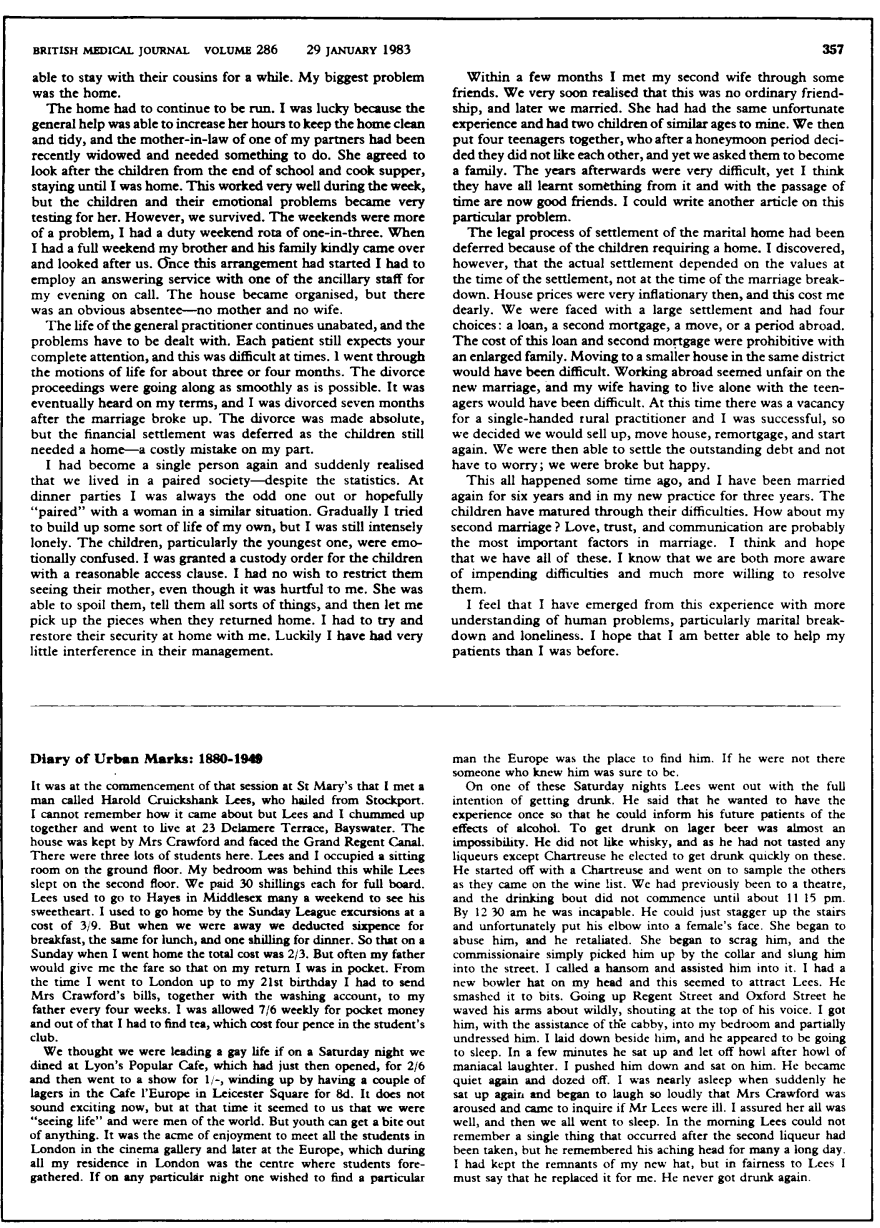

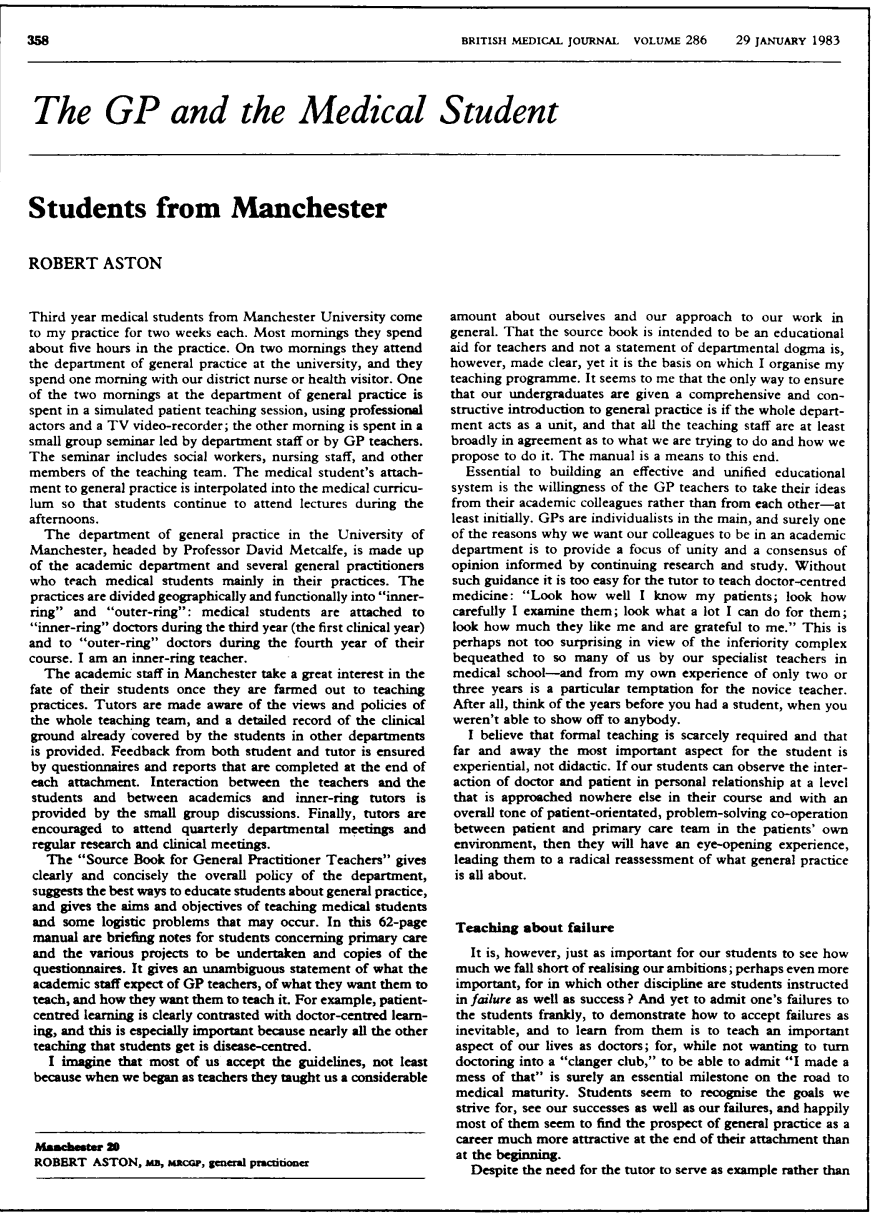

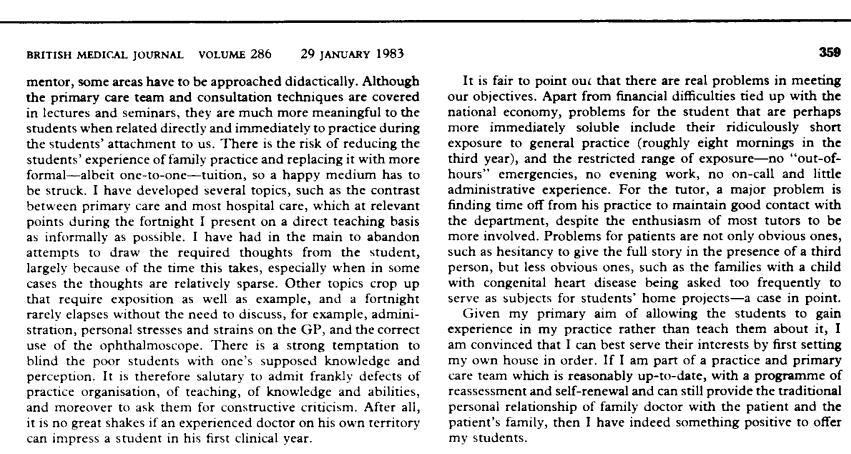

\section{Island Practice}

\section{Prepared for the unpredictable}

ALISTER D GRASSIE

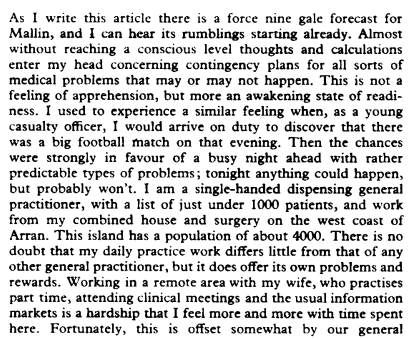

Shiekine, Isle of Arran
ALISTER D GRASSIE, MB, rRCS, general practitioner

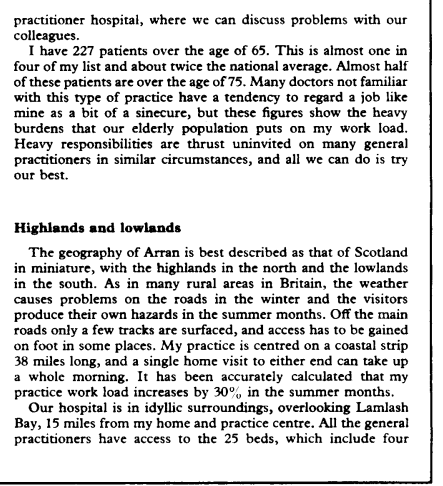

360

obstetric beds. Absolutely every medical emergency passes
chrough irs doors, including those that are destined to require
the skills and technology of a mainland unit. There is a modern

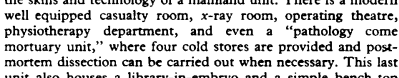
mortem dissection can be carried out when necessary. This las
unit also houses a library-in-embryo and a simple bench top
"laboratory" for side-room rechniques.
The obstetric unit is on a separate level and has a ward with
The Tour beds for antenatal and postrnatal patients. There is
separate delivery room, where it is a positive pleasure to atten a woman in labour. In addition to the hospital there is a home
for elderly peopope with 3 beds, provided under part of the
Social Work Act by the local authority. With three general practitioner colleagues, a part time surtegeon, and a part time
anaesthetist, we staff all of these services. Visiting consultants do clinics in obstetrics and gynaccology, gencrail medicinc, car,
nose, and throat diseases, and ophthalmology, and a consultant anaesthectist provides a regular session about evecry six weeks
The core of the primary care team in my practice consists 0 . onc triple duty nurse, one district nurse midwife, and a social
worker. They are not atrached to the practice and are shared by
two neighbouring practices. I also have a receptionist and secretary, who are both part time. II is impossibief for us all to
sit down for a discussion over coffee every morning, but we manage somehow to communicate regularly by telephone, car
radio, and bush telegraph. Communication outside the practic and with colleagues in similar set tups is far more difficuth.
Last year's meeting of the Scottish Inducement Payments Practitioner Association was well attended. I find these meetings
extremely valuable. Most of the general practitioners who itself mainly with practice administration attendance at meetings
is not recognised under section 63 . It is therefore all the more is not recognised under section 63 . It is therefore all the mos
remarkable that so many $G$ Gs turn up from far and wide at
onsiderable personal expense. The real attraction, of course, is considerable personal expense. The real attraction, of course,
in discussing one's work in congenial surroundings with kindred in discussing one's work
spirits. Few of un can attend postsraduatre mectings and lectures
The Scottish Association of General Practitioner Hospitals promises to provide an extremely valuable meeting point for
those working in them. It is a unique opportunity to bring those working in them. It is a unique opportunity to bring
together practitioners from remotet and urban areas alike, whos
common link will be their commitment to the hospital.

Getting to a meeting

I was asked by a colleague to accompany a seriously ill patient
in a helicopter flight to the mainland on my way to the first annual mecting of the Scottish Association of General Pra
titioner Hospitals. The patient had received a spinal injury in road accident and appeared to have transected his cord at a lowe
dorsal level. In addition, he had severe injuries to the face an dorsal level. In addition, he had severe injuries to the face and
iaw. We were storm bound, with no ferries running at all
though I was unaware of this at the time and had arrangeed though I was unaware of this at the time and had arranged
for my wife and another colleague to cover the practice.
Having made some frantic last minute changes of plan, I w Having made some frantic last minute changes of plan, I was
soon crouching in the back of an aircraft, receiving a severe
buffecting by a heavy storm in the Firth of Clyde.

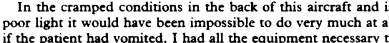
if the patient had vomited. I had all the equipment necessary
deal with such a situation, but it would have been useless in the
circumstances. I have no idea how the poor parient felt, but BRTTISH MEDICAL JOURNAL VOLUME $286 \quad 29$ JNUNRY 1983 was on our side, however, and thanks to the expertise of the
helicopter crew from HMS Gannet we were able to land our patient safely in central Glasgow on what could only be described
as a filthy night. My contribution to this man's well being was as a filthy night. My contribution to this man's well being was
therefore nominal, and full credit to his safery must 80 to my
Collegsyes, who dealt with the problem from the scene of the therefore nominal, and full credit to his safery must go to my
colleagues, who dealt with the problem from the scene of the
accident to the door of the helicopter. Many doctors throughout Britain must be able to quote similar stories. It was refreshing
to be able to talk to some of them at the meering, which, of The "state of readiness" that I mentioned earl lier is borne from an experience of problems quite unfamiliar in most general
practices. A totally unknown pregnant woman on holiday arrives practices. A totally unknown pregnant woman on holiday arrives
at the cottage hospital in established labour in the middle of the

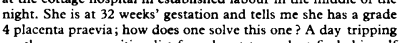
4 placenta praevia; how does one solve this one? A day tripping
gentleman on a waiting list for a harr transplant finds himself

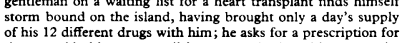
them to tide him over until he can get back to his car on the
mainland. As a dispensing doctor I am required to provide his exotic polypharmacy at an instant's notice. A young woman,
armed with a knife, incarcerates herself in a local hotel room: she is clearly suffering from a serious psychotic illness and needs
urgent psychiatric referral. I am compelled to resort to an urgent psychiactic referral. I am compelled to resort to an
emergency section when she is unable to comprehend my offers emergency section when she is unable to comprehend my offers
of help. This decision to section her sers in motion another
train of thought. The whole operation has to be timed accurately to the arrival of a ferry. Will she run away? What is the weather forecast? Are the ferries running normally? The simple answer
when storm bound is to request thelp from the helicopter at
HMS Gamnet. This service is not always the most suitable for transporting critically ill people. For example, what happens if safely restrain a a schizophrenic patient in a cramped aircraft
without wepout authorised professional help? These problems are
repeatly cropping pu, and the only feature which makes them unusual, if not in some ways unique, is that they happen on an
island. These emergencies are obviously dramatic examples of
how gcography dictares the management, but it colours every
aspect of our work. aspect of our work.
Many practitioners, particulalyly in the city, are struggling for
facilities to perform the kind of work that we are obliged to do here. There is a fund of research material which, with a few
exceptions, remains untapped - but this is beginning to change. exceptions, remains untapped-but this is beginning to change.
The difficulty of access to libraries, staristicicians, royal colleges,
and postgraduate centres is a big hurdle for anyone who contemplates doing research in a remote area. Clearly, more
frequent contact has to be made. In the past we have had to do most of the running, but now some of our colleagues are meecing
us half way by combining a visit with a holidaty Hopefully,
more formal exchanges will take place in the future, with undoubted bencefit to our patients. The pharmaceutical industry
is very aware of the costs of visiting a practice such as ours. I is very aware of the costs of vistiting a practice such as ours.
have been visisted twice by representaiters in the past five years.
There is immense job satisfaction in our work here and, though stressful at times, the stress is not a destructive element.
It is one of the many reasons we choose to remain here. Rural

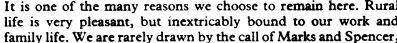
but when we are we arrange a locum and assuage our appetite.
I am convinced that we have closer relationships with our patients, but this is a claim made by many practitioners, and it is
an element that is impossible to measure. When we are old GPS circumstances. I have no idea how the poor patient felt, but I
know that I was feeling very unwell with air sickness. Providence 